\title{
Adding a Bypass to Ensure the Chemical Plant Production
}

\author{
Deming Wang ${ }^{1}$, Ying Peng ${ }^{2}$, Zexi Wang ${ }^{1}$ \\ ${ }^{1}$ Department of Equipment Engineering, Chongqing Real Estate College, Chongqing401331, China \\ ${ }^{2}$ Library, Chongqing Electric Power College, Chongqing400053, China \\ Correspondence: Deming Wang, Department of Equipment Engineering, Chongqing Real Estate College, \\ Chongqing401331, China. Tel.:+86013983229796. E-mail address: dmwang4@163.com
}

Received: June 7, 2016 Accepted: June 22, 2016 Online Published: July 5, 2016

doi:10.5539/ijc.v8n3p50 URL: http://dx.doi.org/10.5539/ijc.v8n3p50

\begin{abstract}
The chilling output of the chiller fluctuated according to the chilling load. When it dropped down below a certain value, the temperature of the supply chilled water flowing out of the chiller would drop down too much. And this would result the chiller being shut down abnormally, because of its low temperature protection. Any this shutdown of the chiller endangered the production continuity and security, and caused a certain economic losses. A bypass, which was from the outlet of the chiller's condenser to the chilled water filter inlet, was added to the chilling system. Through this bypass, some cooling water was introduced from the cooling water circulation into the chilled water circulation. Then the temperature of the supply chilled water flowing out of the chiller was promoted. With experiments, and by the aid of thermodynamics analysis, the amount of introduced cooling water, which could be introduced to promote the supply chilled water temperature for maintaining the chiller running normally, was researched. Ultimately, a certain amount of introduced cooling water, at which the chiller would no longer stop abnormally at any chilling load, was determined. And the energy lose caused by the introduced cooling water was less than 5 percent the rated output of the chiller. Compared with the chiller rated output, this energy lose was so small that it could be neglected.
\end{abstract}

Keywords: bypass, chemical plant, chilling load, chilling output, production continuity

\section{Introduction}

Chilling system was generally applied to many chemical plants for cooling their production processes, and their productions were often fluctuating. The chilling load (i.e., the required chilling load for production processes) varied much according to its production fluctuation. This caused the chilling output of the chiller varied much too. The chilling output could automatically adjust to fit the chilling load in an available range. But, when the chilling load was too small, the chiller could no longer adjust to fit it. The temperature of the supply chilled water flowing out of the chiller, which was monitored to prevent the chiller being frozen, dropped down and down, until to that of the chiller's low temperature protection. Then the chiller would be shut down abnormally, and restarted up in many minutes. Therefore, the security and continuity of the production were seriously affected, and the corresponding economic losses occurred at the same time. In a chemical plant, this case often occurred. In order to solve this problem, a bypass was added to the chilling system. This bypass was from the outlet of the chiller's condenser to the chilled water filter inlet. Through this bypass, some cooling water could be introduced to the chilled water circulation, to promote the supply chilled water temperature for maintaining the chiller running normally, even if the chilling load drop down below its available adjusting range.

This method of using bypass in the system was widely applied to engineering practice. In the refrigerating engineering field, Ma \& Wang (2011) developed bypass check valve to enhance the overall system performance; Choi, B. Kim, Kang, \& K. Kim (2011), and J. Kim, Choi, \& K. Kim (2015) applied the bypass for defrosting in the heat pump; Tuo \& Hrnjak (2012) showed that flash gas bypass method could improve refrigerant distribution and reduce pressure drop on refrigerant side in the mobile air conditioning system; Byun, Lee, \& Jeon (2008) discovered that the hot gas bypass method was useful for retarding the formation and growth of frost at the outdoor coil and for improving the performance of the air source heat pump; Tso, Wong, Jolly, \& Ng (2001) conducted simulation studies using a mathematical model to compare the performance of the hot-gas by-pass control and the suction modulation control in refrigerated shipping containers, their results showed that the suction modulation control strategy was the more energy efficient of the two; Elbel \& Hrnjak (2004) found that the performance of transcritical R744 systems with direct expansion could be significantly improved by implementing a flash gas bypass; it was demonstrated by Wang, Han, Shi, 
\& $\mathrm{Li}$ (2012) that suction gas bypass was an effective regulating method of scroll compressor, and it could reduce the inner compression loss under over compression conditions and largely decrease the heating/cooling capacity of the refrigeration system; Tuo \& Hrnjak (2014) used flash gas bypass for vapor-liquid separation in vapor compression systems; Huang, Li, \& Yuan (2009) suggested that the hot-gas bypass defrosting could overcome the main disadvantages of the reverse-cycle defrosting method; Ding, Zhang, \& Lu (2004) proved bypass two-circuit cycle freezers with one compressor were more efficient than two-evaporator in series cycle freezers in reducing the greenhouse gas emissions.

In the other engineering field, the bypass method also applied widely to the practice. For instance, W. Chen, $\mathrm{H}$. Chen, Shi, Xue, Chong, \& Yan (2016) installed a bypass in the low pressure district of the ejector to enhance its capacity; Zaccaria \& Traverso (2016) regarded that the cold air bypass could be used for thermal management of the fuel cell. Luo, Xia, \& Sun (2013) promised that bypass adjustment could improve operational efficiency and reduce heat exchanger network costs; W. Wang, X. Wang, \& Liu (2011) used the bypass system for intermediate pressure start-up of a turbine unit; Yang, $\mathrm{Pu}$, Wong, \& Moore (2009) applied by-pass valve to reduce the overshoot and allow some exhaust compressed air to be reused in the pneumatic drive, they showed that a $12-28 \%$ saving in energy use could be acquired and meanwhile the position accuracy is maintained, compared with the traditional control of the motion of the asymmetric cylinder; research by Yoon, J. Lee, S. Lee, Tak, M. Kim, K. Kim, \& Park (2013) supported that the bypass flow distribution was reduced throughout the entire core regions in block type very high temperature reactor (VHTR), and the bypass flow ratios at the inlet and the outlet were reduced by $36.19 \%$ and $14.66 \%$, respectively; Ren \& He (2009) designed a continuous circulating valve, in which a bypass was applied, to reduce oil drilling pipe accidents such as sticking and so on.

In this chemical plant, with experiments, and by the aid of thermodynamics analysis, the amount of introduced cooling water was researched. Ultimately, a certain amount of introduced cooling water, at which the chiller would no longer stop abnormally at any chilling load, was determined. And the energy lose caused by the introduced cooling water was less than 5 percent the rated output of the chiller at this introduced cooling water amount. Compared with the chiller rated output, this energy lose was so small that it could be neglected. At the same time, the security and continuity of its production were ensured, and the corresponding economic losses were avoided.

\section{Case Study}

The chilling system of this plant was composed of cooling water and chilled water circulations. The Cooling water circulation consisted of cooling tower, cooling water tank, filter, cooling water pump, and condenser of the chiller, etc. The chilled water circulation consisted of expansion tank, distributor, collector, filter, chilled water pump, evaporator of the chiller, as well as the production processes within which the chilling load was needed. In addition, the outflow and inflow of the chiller were called as the supply and return water, respectively. And the supply and return water pipes were shown with solid lines and dashed lines, respectively, as shown in figure 1.

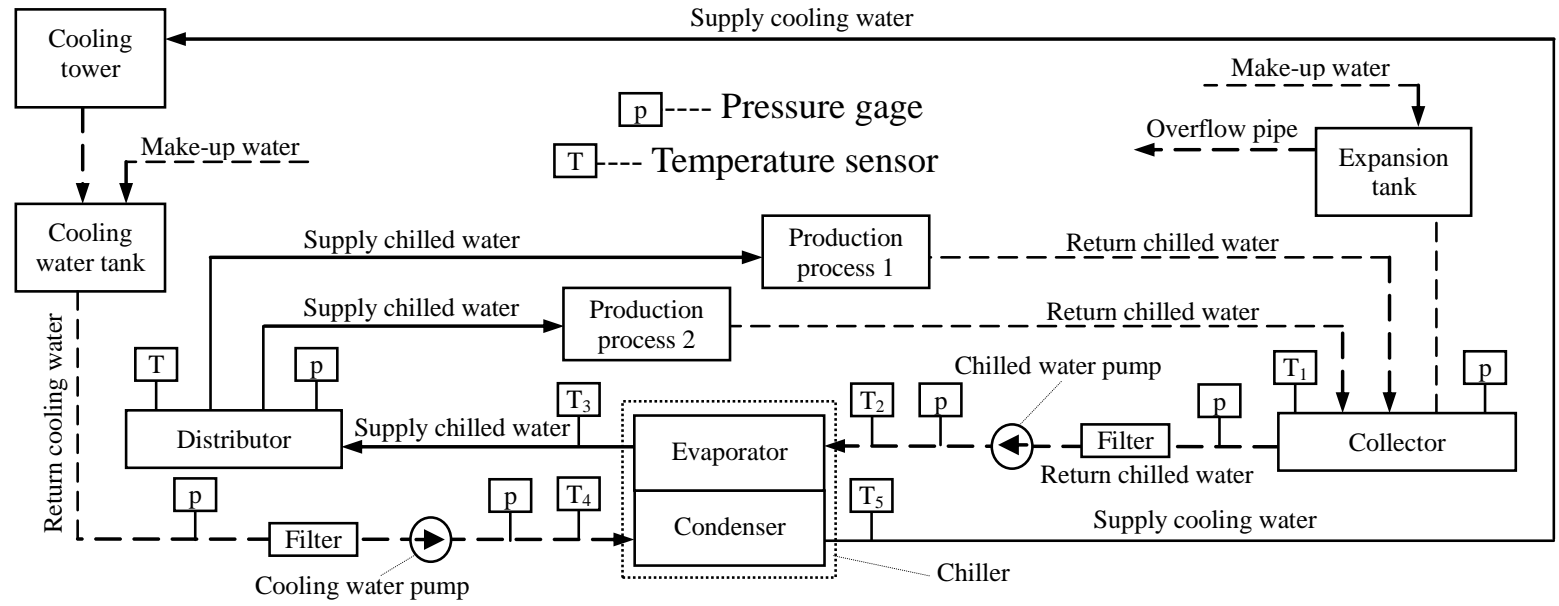

Figure1. Process of the chilling system

The design running data of the chilling system was shown in table 1 . The chiller rated output was $220 \mathrm{kw}$. The temperature of the return chilled water $t_{l}$ was $10^{\circ} \mathrm{C}$, that of the chiller condenser's inflow water $t_{2}$ was equal to $t_{l}$ in this system, and that of the supply chilled water $t_{3}$ was $5^{\circ} \mathrm{C}$. They were measured by thermometers $\mathrm{T}_{1}, \mathrm{~T}_{2}$ and $\mathrm{T}_{3}$, respectively. The temperature of the return cooling water $t_{4}$ was $30^{\circ} \mathrm{C}$, and that of the supply cooling water $t_{5}$ was $35^{\circ} \mathrm{C}$. They were measured by thermometer $\mathrm{T}_{4}$ and $\mathrm{T}_{5}$, respectively. 
Table 1. Design running data of the chilling system

\begin{tabular}{cccccccc}
\hline \multicolumn{2}{c}{ Chilling output, $O$} & \multicolumn{2}{c}{ Chilling load, $L$} & \multicolumn{2}{c}{ Chilled water temperature } & \multicolumn{2}{c}{ Cooling water temperature } \\
\hline Rated, & Minimum, & Maximum, & Minimum, & Return, & Supply, & Return, & Supply, \\
$O_{r}, \mathrm{kw}$ & $O_{\min }, \mathrm{kw}$ & $L_{\max }, \mathrm{kw}$ & $L_{\min }, \mathrm{kw}$ & $t_{l},{ }^{\circ} \mathrm{C}$ & $t_{3},{ }^{\circ} \mathrm{C}$ & $t_{4},{ }^{\circ} \mathrm{C}$ & $t_{5},{ }^{\circ} \mathrm{C}$ \\
\hline 220 & 66 & 175 & 30 & 10 & 5 & 30 & 35 \\
\hline
\end{tabular}

Note: the return and supply mean the return and supply water temperatures, respectively.

The chilling output of the chiller could be automatically adjusted from $30 \%$ to $100 \%$ its rated output, i.e., from $66 \mathrm{kw}$ to $220 \mathrm{kw}$; and the chilling load was fluctuating from $30 \mathrm{kw}$ to $175 \mathrm{kw}$ according to the production. Generally, the chilling output was nearly equal to the chilling load during production operations, because all the chilled water pipes and related equipments were thermally insulated. In fact, the chilling load often fluctuated to the value below $66 \mathrm{kw}$, even to $30 \mathrm{kw}$, while the chilling output could not drop down to that one. Then the chilling system would be running with $66 \mathrm{kw}$ of the chilling output and with less than $66 \mathrm{kw}$ of the chilling load, the supply chilled water temperature would be dropping down continuously, until to $3^{\circ} \mathrm{C}$ and causing the chiller shutdown. This case often occurred. Any shutdown would make the chiller restart up in 20 minutes according to its procedural protection. The security and continuity of production were affected, and some economic losses occurred.

\section{Research Method}

In order to ensure the security and continuity of production, a bypass, which was from the outlet of the chiller's condenser to the chilled water filter inlet, was added to the chilling system, as shown with bold solid lines in figure 2 . Through this bypass, some cooling water could be introduced into the chilled water circulation, to ensure the supply chilled water temperature not dropping down to $3^{\circ} \mathrm{C}$, and maintain the chiller running continuously.

A modulating valve and a flow meter were installed on the bypass pipe, to modulate the introduced cooling water flow rates. With experiments, and by the aid of thermodynamics analysis, the amount of the introduced cooling water for maintaining the chiller running normally was researched.

When the supply chilled water temperature $t_{3}$ dropped down to $3^{\circ} \mathrm{C}$, the chiller would shut down because of its procedural protection. During any experiment, when it dropped down to $3.5^{\circ} \mathrm{C}$, it was regarded that this experiment failed.

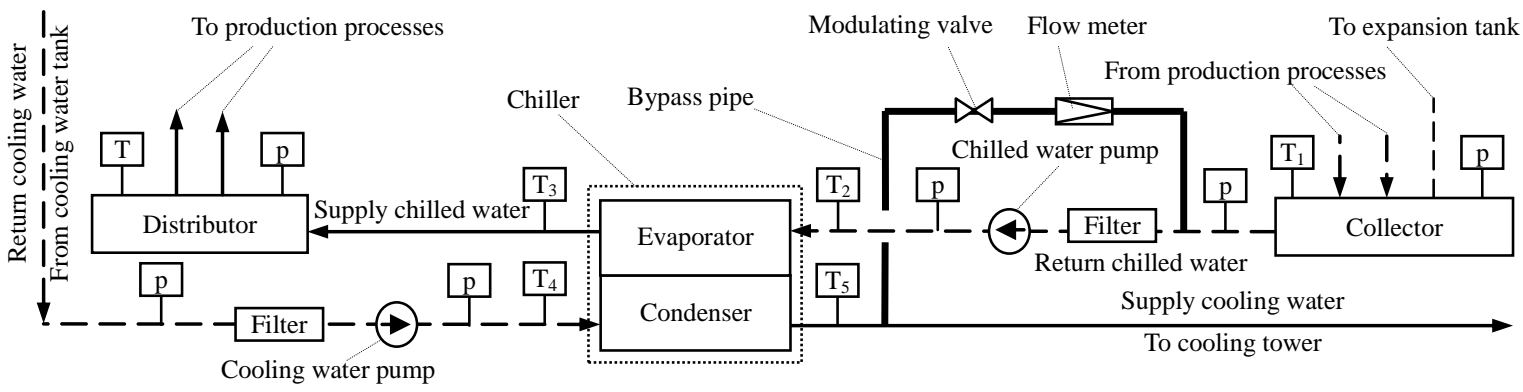

Figure 2. Process of the chilling system with bypass

On the other hand, when the supply chilled water temperature $t_{3}$ was beyond $8^{\circ} \mathrm{C}$, it would dissatisfy production operation. During any experiment, when it rose up to $7.5^{\circ} \mathrm{C}$, it was regarded that this experiment failed.

\section{Results and Discussion}

\subsection{Thermodynamics Analysis}

Because all the pipes and equipments, through which chilled water ran, were covered with thermal insulation layers, the heat lose could be neglected. Based on principle of energy balance according to the heat transfer edited by Yang \& Tao (2006), the chilling output of the chiller with introduced cooling water can be expressed as:

$$
O=\rho c \delta Q\left(t_{5}-t_{1}\right)+\rho c(Q+\delta Q)\left(t_{1}-t_{3}\right)
$$

Here: $O$ means the chilling output of the chiller, kw; $\rho$ means the density of water, $\mathrm{kg} / \mathrm{L} ; c$ means the heat capacity of the water, $\mathrm{kJ} /\left(\mathrm{kg} \cdot{ }^{\circ} \mathrm{C}\right) ; \delta Q$ means the introduced cooling water amount, $\mathrm{L} / \mathrm{s} ; t_{5}$ means the supply cooling water temperature, ${ }^{\circ} \mathrm{C} ; t_{1}$ means the return chilled water temperature, ${ }^{\circ} \mathrm{C} ; t_{3}$ means the supply chilled water temperature, ${ }^{\circ} \mathrm{C}$; $Q$ means the amount of chilled circulating water, L/s.

In the right side of equation (1), the first item denotes the load for chilling the introduced cooling water from temperature $t_{5}$ to $t_{l}$, the second item denotes the load for chilling both the introduced cooling water and chilled 
circulating water from temperature $t_{1}$ to $t_{3}$. At the same time, the corresponding chilling load for the production operation was required as below:

$$
L=\rho c Q\left(t_{1}-t_{3}\right)
$$

Here: $L$ means the chilling load for the production operation, kw. Solving equations (1) and (2), the introduced cooling water amount can be obtained as below:

$$
\delta Q=\frac{O-L}{\rho c\left(t_{5}-t_{3}\right)}
$$

Define the chilling load ratio as:

$$
\alpha=\frac{L}{O_{r}}
$$

Here: $\alpha$ means the chilling load ratio; $O_{r}$ means the chiller rated output, kw. And name the chilling output ratio as:

$$
\beta=\frac{O}{O_{r}}
$$

Here: $\beta$ means the chilling output ratio. Then the introduced cooling water amount $\delta Q$ can be expressed as:

$$
\delta Q=\frac{O_{r}}{\rho c\left(t_{5}-t_{3}\right)}(\beta-\alpha)
$$

According to equation (6), the chilling output ratio $\beta$ might be written as follow:

$$
\beta=\frac{\rho c\left(t_{5}-t_{3}\right) \delta Q}{O_{r}}+\alpha
$$

Because $\rho, c$ and $O_{r}$ are almost constant values, the chilling output ratio $\beta$ relates to $t_{3}, t_{5}$ and $\alpha$.

\subsection{Experiment Results}

Experiment results were shown in figure 3 and figure 4, the chilling output ratio $\beta$ were obtained according equation (7). And all those experiment results could ensure non-stop of the chiller and continuity of the production.

At the chilling load of $30 \mathrm{kw}$, i.e., $\alpha=0.14$, it was shown in figure 3 that:

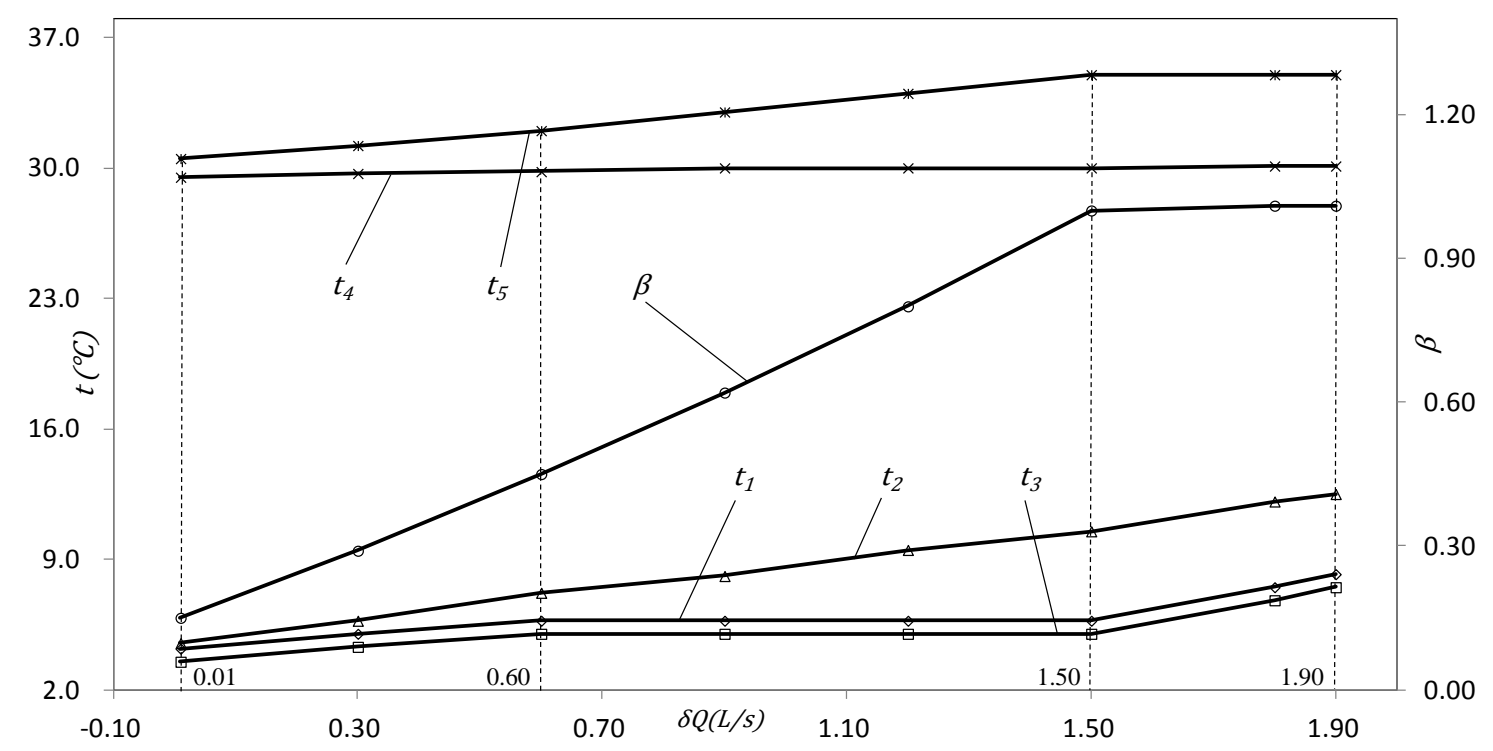

Figure 3. Experiment results while $\alpha=0.14$

The minimum introduced cooling water amount was $0.01 \mathrm{~L} / \mathrm{s}$, while the $t_{3}=3.5^{\circ} \mathrm{C}$ and the $\beta=0.15$; and the maximum 
amount was $1.90 \mathrm{~L} / \mathrm{s}$, while the $t_{3}=7.5^{\circ} \mathrm{C}$ and the $\beta=1.00$.

In the range between $0.6 \mathrm{~L} / \mathrm{s}$ and $1.5 \mathrm{~L} / \mathrm{s}$ of the $\delta Q$, the $t_{3}$ stayed the same with the $\delta Q$ increasing, because the chiller could automatic adjust its output to maintain $t_{3}$ at $5^{\circ} \mathrm{C}$; in the other ranges, the $t_{3}$ was rising with the $\delta Q$. The change trend of the $t_{1}$ was the same as the $t_{3}$, because the chilling load was not changed, i.e., $\alpha=0.14$. The $t_{2}$ was always rising with the $\delta Q$.

The $t_{4}$ came nearer to $30^{\circ} \mathrm{C}$, because it was determined by its environment wet bulb temperature; the $t_{5}$ and $\beta$ were rising before $1.50 \mathrm{~L} / \mathrm{s}$ of the $\delta Q$. After $1.5 \mathrm{~L} / \mathrm{s}$ of the $\delta Q$, the $t_{5}$ and $\beta$ rose up to $35^{\circ} \mathrm{C}$ and 1.00 , and stayed the sames, respectively.

At the chilling load of $175 \mathrm{kw}$, i.e., $\alpha=0.80$, it was shown in figure 4 that:

The minimum introduced cooling water amount was $0.00 \mathrm{~L} / \mathrm{s}$, i.e., no cooling water introduced, while the $t_{3}=5.0^{\circ} \mathrm{C}$ and the $\beta=0.80$; and the maximum amount was $0.42 \mathrm{~L} / \mathrm{s}$, while the $t_{3}=7.5^{\circ} \mathrm{C}$ and the $\beta=1.00$.

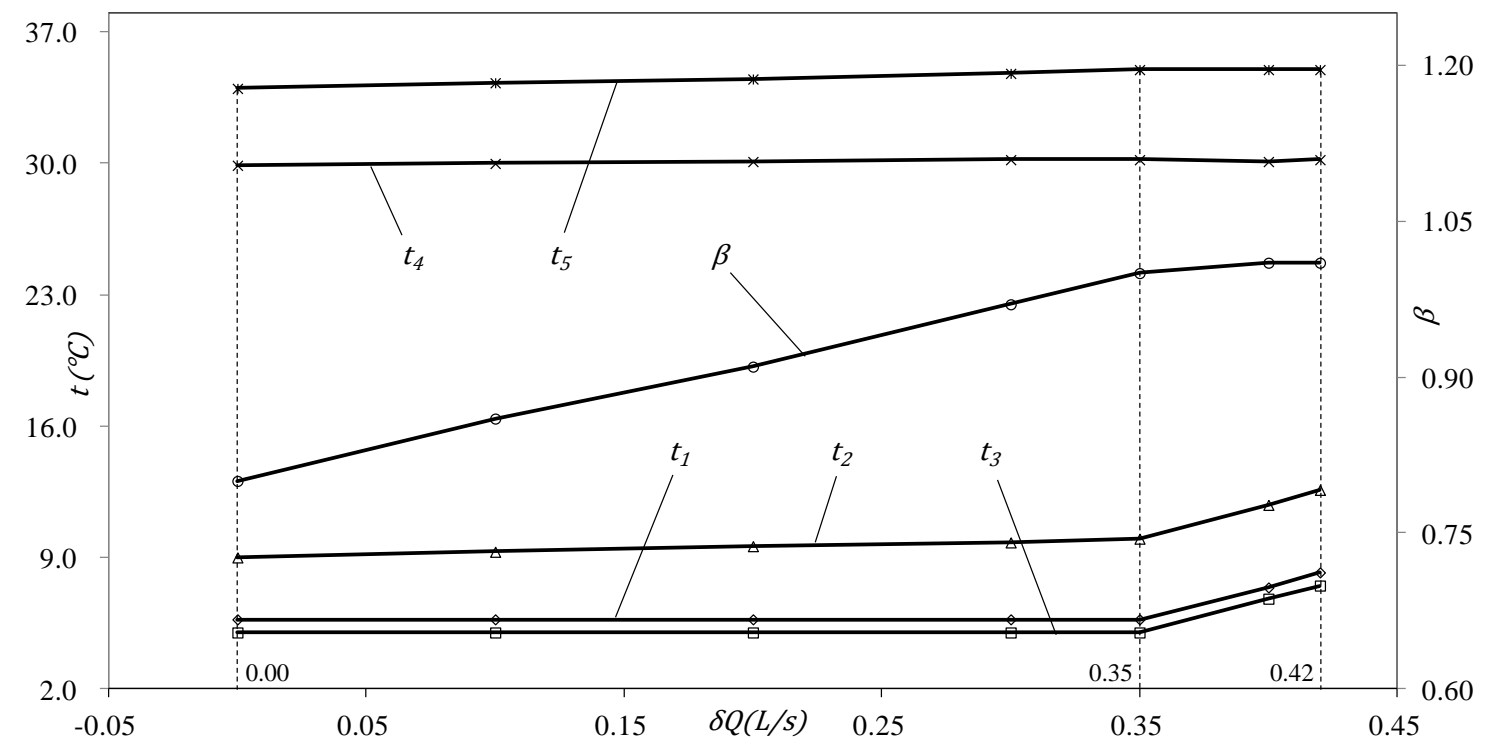

Figure 4. Experiment results while $\alpha=0.80$

The $t_{3}$ stayed the same because the chiller could automatic adjust its output to keep it at $5{ }^{\circ} \mathrm{C}$, until it began to rise after $0.35 \mathrm{~L} / \mathrm{s}$ of the $\delta Q$. The change trend of the $t_{l}$ was the same as the $t_{3}$, because the chilling load was not changed, i.e., $\alpha=$ 0.80 . The $t_{2}$ was rising with the $\delta Q$, yet it was rising more sharply after $0.35 \mathrm{~L} / \mathrm{s}$ of the $\delta Q$.

The $t_{4}$ came nearer to $30^{\circ} \mathrm{C}$, because it was determined by its environment wet bulb temperature. The $t_{5}$ and $\beta$ were rising, until they rose up to $35^{\circ} \mathrm{C}$ and 1.00 and stayed the sames after $0.35 \mathrm{~L} / \mathrm{s}$ of the $\delta Q$, respectively.

From figure 3 and figure 4, it could be obtained that the $\delta Q$ between $0.01 \mathrm{~L} / \mathrm{s}$ and $0.42 \mathrm{~L} / \mathrm{s}$ could satisfy any chilling load. Considering the parameter fluctuation and energy conservation, the $\delta Q$ was controlled at $0.10 \mathrm{~L} / \mathrm{s}$. At this amount, the energy lose caused by the introduced cooling water was nearly $10 \mathrm{kw}$, which was less than $5 \%$ the rated output of the chiller. Compared with the chiller rated output, this energy lose was so small that it could be neglected.

At the same time, because the chiller would no longer shut down abnormally, the security and continuity of the production were ensured, and the corresponding economic losses were avoided.

\section{Conclusion}

In some chemical plants, the production often fluctuated much, caused the chiller stopped abnormally. This seriously endangered the production. In order to keep the chiller running normally, bypass was applied to introduce some cooling water into chilled water circulation. Thermodynamics analysis and experiment study were conducted to determine the introduced amount. The chilled and cooling water temperatures and the chilling output ratio, which changed with the introduced cooling water amount, were obtained. Ultimately, a certain amount of introduced cooling water, at which the chiller would no longer stop abnormally at any chilling load, was determined. And the energy lose caused by the introduced cooling water was less than $5 \%$ the rated output of the chiller at this amount. 


\section{References}

Byun, J. S., Lee, J. H., \& Jeon, C. D. (2008). Frost retardation of an air-source heat pump by the hot gas bypass method. International Journal of Refrigeration, 31, 328-334. http://www.sciencedirect.com/science/article/pii/S01407007070008 -49

Chen, W. X., Chen, H. Q., Shi, C. Y., Xue, K. K., Chong, D. T., \& Yan, J. J. (2016). A novel ejector with a bypass to enhance the performance. Applied Thermal Engineering, 93, 939-946. http://www.sciencedirect.com/science/article/pii /S135943111501114X

Chen, W. X., Chen, H. Q., Shi, C. Y., Xue, K. K., \& Chong, D. T. (2016). Impact of operational and geometrical factors on ejector performance with a bypass. Applied Thermal Engineering, 99, 476-484. http://www.sciencedirect.com/science /article/pii/S1359431116300242

Choi, H. J., Kim, B. S., Kang, D., \& Kim, K. C. (2011). Defrosting method adopting dual hot gas bypass for an air-to-air heat pump. Applied Energy, 88(12), 4544-4555. http://www.sciencedirect.com/science/article/pii/S0306261911003345

Ding, G. L., Zhang, C. L., \& Lu, Z. L. (2004). Dynamic simulation of natural convection bypass two-circuit cycle refrigerator-freezer and its application: Part I: component models. Applied Thermal Engineering, 24, 1513-1524. http://www.sciencedirect.com/science/article/pii/S1359431103004034

Elbel, S., \& Hrnjak, P. (2004). Flash gas bypass for improving the performance of transcritical R744 systems that use microchannel evaporators. International Journal of Refrigeration, 27, 724-735. http://www.sciencedirect.com/science/ar -ticle/pii/S0140700704001501

Huang, D., Li, Q. X., \& Yuan, X. L. (2009). Comparison between hot-gas bypass defrosting and reverse-cycle defrosting methods on an air-to-water heat pump. Applied Energy, 86, 1697-1703. http://www.sciencedirect.com/science/article/pii /S0306261908003012

Kim, J., Choi, H. J., \& Kim, K. C. (2015). A combined dual hot-gas bypass defrosting method with accumulator heater for an air-to-air heat pump in cold region. Applied Energy, 147, 344-352. http://www.sciencediect.com/science/article /pii/S030626191500 -2597

Luo, X. L., Xia, C. K., \& Sun, L. (2013). Margin design, online optimization, and control approach of a heat exchanger network with bypasses. Computers \& Chemical Engineering, 53, 102-121. http://www.sciencedirect.com/science/article/pii/S0098135413000446

Ma, Z. J., \& Wang, S. W. (2011). Enhancing the performance of large primary-secondary chilled water systems by using bypass check valve. Energy, 36, 268-276. http://www.sciencedirect.com/science/article/pii/S0360544210006055

Ren, L. C., \& He, D. S. (2009). Design of continuous circulation valve. China Petroleum Machinery, 37, $129-132$. http://lib.cqvip.com/qk/94770X/200909/31438539.html

Tso, C. P., Wong, Y. W., Jolly, P. G., \& Ng, S. M. (2001). A comparison of hot-gas by-pass and suction modulation method for partial load control in refrigerated shipping containers. International Journal of Refrigeration, 24, 544-553. http:// www.sciencedirect.com/science/article/pii/S0140700700000529

Tuo, H. F., \& Hrnjak, P. (2014). Enhancement of vapor-liquid separation in vertical impact T-junctions for vapor compression systems with flash gas bypass. International Journal of Refrigeration, 40, 43-50. http://www.sciencedirect.com/science/article/pii/S0140700713002971

Tuo, H. F., \& Hrnjak, P. (2014). Vapor-liquid separation in a vertical impact T-junction for vapor compression systems with flash gas bypass. International Journal of Refrigeration, 40, 189-200. http://www.sciencedirect.com/science/article/pii/S0140700713003058

Tuo, H. F., \& Hrnjak, P. (2012). Flash gas bypass in mobile air conditioning system with R134a. International Journal of Refrigeration, 35, 1869-1877. http://www.sciencedirect.com/science/article/pii/S0140700712001272

Wang, B. L., Han, L. J., Shi, W. X., \& Li, X. T. (2012). Modulation method of scroll compressor based on suction gas bypass. Applied Thermal Engineering, 37, 183-189. http://www.sciencedirect.com/science/article/pii/S1359431111 -006338

Wang, W. B., Wang, X. D., \& Liu, D. J. (2011). IP start-up control for 300MW turbine unit with bypass system. Procedia Engineering, 16, 493-498. http://www.sciencedirect.com/science/article/pii/S1877705811026166

Yang, A. M., Pu, J. S., Wong, C. B., \& Moore, P. (2009). By-pass valve control to improve energy efficiency of pneumatic drive system. Control Engineering Practice, 17, 623-628. 
http://www.sciencedirect.com/science/article/pii/S096706610 -8001883

Yang, S. M., \& Tao, W. Q. (2006). Heat transfer (4th ed.). Beijing: Higher education press.

Yoon, S. J., Lee, J. H., Lee, S. M., Tak, N. I., Kim, M. H., Kim, K. Y., \& Park, G. C. (2013). Numerical and Experimental Investigation on Labyrinth Seal Mechanism for Bypass Flow Reduction in Prismatic VHTR Core. Nuclear Engineering and Design, 262, 525-534.

http://www.sciencedirect.com/science/article/pii/S0029549313002938

Zaccaria, V., \& Traverso, A. (2016). Transfer function development for SOFC/GT hybrid systems control using cold air bypass. Applied Energy, 165, 695-706. http://www.sciencedirect.com/science/article/pii/S0306261915016670

\section{Copyrights}

Copyright for this article is retained by the author(s), with first publication rights granted to the journal.

This is an open-access article distributed under the terms and conditions of the Creative Commons Attribution license (http://creativecommons.org/licenses/by/4.0/). 